\title{
BMJ Global Heath Chronic kidney disease and the global NCDs agenda
}

To cite: Neuen BL, Chadban SJ, Demaio AR, et al. Chronic kidney disease and the global NCDs agenda. BMJ Glob Health 2017;2:e000380. doi:10.1136/ bmjgh-2017-000380

Received 22 April 2017 Revised 21 May 2017 Accepted 22 May 2017

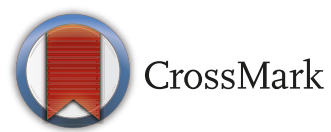

${ }^{1}$ Department of Renal Medicine Royal Prince Alfred Hospital, Sydney, Australia

${ }^{2}$ Renal and Metabolic Division George Institute for Global Health, Sydney, Australia ${ }^{3}$ Charles Perkins Centre, University of Sydney, Sydney, Australia

${ }^{4}$ World Health Organization, Geneva, Switzerland ${ }^{5}$ Centre for Kidney Disease Research, University of Queensland, Brisbane, Australia ${ }^{6}$ Department of Nephrology, Princess Alexandra Hospital, Brisbane, Australia

${ }^{7}$ Translational Research Institute, Brisbane, Australia

${ }^{8}$ Department of Renal Medicine, Royal North Shore Hospital, Sydney, Australia

Correspondence to Dr Brendon Lange Neuen; brendon.neuen@sswahs.nsw. gov.au

\author{
Brendon Lange Neuen, ${ }^{1,2}$ Steven James Chadban, ${ }^{1,3}$ Alessandro Rhyl Demaio, \\ David Wayne Johnson, ${ }^{5,6,7}$ Vlado Perkovic ${ }^{2,8}$
}

2017 is an important year for the international nephrology community. March 9 was World Kidney Day, the theme this year being 'Kidney disease and obesity: healthy lifestyles for healthy kidneys', highlighting the crucial link between the kidneys and metabolic and cardiovascular health. In April, the Global Kidney Health Atlas, one of the largest health-related country capacity reviews in history, was launched at the World Congress of Nephrology in Mexico City. The Atlas, a first for the nephrology community, is a multinational cross-sectional survey designed to assess need and capacity for kidney care worldwide and provide the foundation for a global surveillance network for chronic kidney disease $(\mathrm{CKD})$ care.

CKD is an enormous public health issue, the tide of which continues to inexorably rise. In the 2015 Global Burden of Disease Study, kidney disease was the 12th most common cause of death, accounting for 1.1 million deaths worldwide. ${ }^{1}$ Overall CKD mortality has increased by $31.7 \%$ over the last 10 years, making it one of the fastest rising major causes of death, alongside diabetes and dementia. ${ }^{1}$ In the same study, CKD ranked as the 17 th leading cause of global years lost of life, an $18.4 \%$ increase since 2005, and the third largest increase of any major cause of death. ${ }^{1}$ This is in stark contrast to other non-communicable diseases, for example cardiovascular disease and chronic obstructive pulmonary disease, where global years lost of life fell during the same time period $(-10.2 \%$ and $-3.0 \%$, respectively).

Unabated growth in the incidence of diabetic kidney disease, underpinned by a global imbalance between overnutrition and inadequate physical inactivity causing overweight and obesity, is the key driver of CKD burden. Between 2005 and 2015, the prevalence of diabetic kidney disease increased by $39.5 \%$ globally. ${ }^{1}$ In Mexico, the country with the highest CKD death rate in the world, more than half of all cases of end-stage kidney disease were attributable to diabetes. ${ }^{1}$ Similar patterns have been reported in China and India, signifying epidemiological shifts in metabolic and cardiovascular risk factors, particularly in middle-income countries.

At the same time, the rising burden of CKD disproportionately impacts low-income and middle-income countries where growth in obesity and diabetes is greatest. The hard outcomes of CKD, namely premature cardiovascular death or progression to end-stage kidney disease, are more likely to occur in people with CKD in India than in North America due to inadequate risk factor management, for example treatment with ACE inhibitors and/or oral hypoglycaemic agents. ${ }^{2}{ }^{3}$ Latin America has the highest CKD death rate in the world. ${ }^{1}$ For those who reach end-stage kidney disease, dire consequences await them, with serious global inequities in the availability of renal replacement therapy, primarily due to cost. ${ }^{4}$ In 2010, according to conservative estimates, over half of all people requiring renal replacement therapy worldwide died due to a lack of access to dialysis or transplantation. The largest disparities in access to renal replacement were in Africa, particularly middle and eastern Africa, where less than 3\% of people requiring renal replacement therapy receive it. ${ }^{4}$ The growing burden of CKD therefore falls on countries least equipped to provide the costly but life-saving therapies of dialysis or transplantation. As a result, people with end-stage kidney disease continue to die in spite of established treatment options. The huge cost associated with providing renal replacement therapy provides a compelling economic incentive for improving the prevention, detection and management of CKD in low-income and middle-income countries.

Efforts to do this must be developed, tested and incorporated into existing national non-communicable diseases (NCDs) programmes. While three-quarters of countries have an overarching NCDs policy or 
strategy, more than half $(53 \%)$ have no management guidelines or strategy for improving the care of people with CKD (either specifically or within a broader NCDs strategy). ${ }^{5}$ Population screening for CKD has been shown to be cost-effective in some studies when taking into account incident end-stage kidney disease, and fatal and non-fatal cardiovascular events. ${ }^{6}$ Targeted screening for CKD in people with hypertension and diabetes is a more economically viable strategy and occurs in many countries, but less than a quarter (24\%) have a CKD detection programme based on national guidelines or policies. ${ }^{5}$

As highlighted by World Kidney Day, obesity is a significant marker of risk for CKD, independent of hypertension and diabetes, and therefore represents another important target for CKD screening and early detection. ${ }^{7}$ There is evidence that weight reduction in CKD reduces proteinuria and blood pressure and may slow decline in renal function. ${ }^{8}$ Population strategies aimed at curbing the rise in obesity or assisting individuals in losing weight are therefore likely to have beneficial effects on the incidence and progression of $\mathrm{CKD}$, as well as simultaneously improving other aspects of cardiometabolic health.

For people with CKD, there must be a focus on implementing proven, cost-effective treatments for as many people as possible, taking into account local needs and human and economic resources. In the majority of low-middle-income countries, management of risk factors to prevent CKD progression and the treatment of its complications are excluded from public funding (55\% and $58 \%$, respectively). ${ }^{2}$ Monitoring of CKD using estimated glomerular filtration rate and urinary albumin creatinine ratio is available in less than $20 \%$ of low-middle-income countries. ${ }^{9}$ Strengthening primary care services will be essential, given most CKD is managed in this setting and global shortages in nephrologists $(35 \%$ of low-income countries lack a nephrology training programme ${ }^{5}$ ). Successful examples include Cuba, Uruguay and Chile, where programmes to integrate CKD screening, detection and treatment in primary care have been introduced. ${ }^{10}$

Evaluating practice patterns and current health system capacity to deliver kidney healthcare is also critically important. The Global Kidney Health Atlas provides important information on CKD risk factors (biological, behavioural and sociodemographic including obesity and diabetes), the burden and consequences of CKD, and gaps in specific kidney care areas in different countries around the world based on the six health system building blocks. ${ }^{51112}$ It also provides the foundation for a global CKD surveillance network to facilitate the development and evaluation of implementation strategies for including CKD in the global health agenda. For the first time, the Atlas clearly details the significant inter-regional and intraregional variability and gaps in kidney care across countries and regions, which are summarised in tables 1 and 2.

The data contained within the Atlas have significant policy implications. Particularly across low-income and middle-income countries, the Atlas provides both evidence and opportunities for advocacy: improving access to affordable essential medications, and establishing health information systems (eg, renal registries) to capture reliable information on the burden of CKD, and to promote more investment and a targeted research agenda to improve understanding of kidney disease burden, process of care, outcomes monitoring and testing of novel interventions. ${ }^{5}{ }^{12}$ It provides advocacy organisations and health workforces with the data to engage key government and non-government stakeholders to support countries in improving the quality of kidney care and to hold countries to account by measuring country and region progress over time.

More generally, rapid urbanisation, resulting in obesity and physical inactivity, is driving changes in CKD risk factor prevalence worldwide. Poor diet is now the leading risk factor for deaths and disability worldwide, a fact recognised by the United Nations Decade

\begin{tabular}{|c|c|c|c|c|}
\hline & $\begin{array}{l}\text { Low-income } \\
(\%)\end{array}$ & $\begin{array}{l}\text { Low-middle- } \\
\text { income (\%) }\end{array}$ & $\begin{array}{l}\text { Upper-middle- } \\
\text { income (\%) }\end{array}$ & High-income (\%) \\
\hline Access to serum creatinine and eGFR in primary care & - & 18 & 40 & 68 \\
\hline Access to quantitative urinalysis in primary care & - & 32 & 43 & 71 \\
\hline Governmental recognition of CKD as a health priority & 59 & 50 & 17 & 29 \\
\hline Government funds all aspects of CKD care & 13 & 21 & 40 & 53 \\
\hline $\begin{array}{l}\text { Availability of CKD management and referral } \\
\text { guidelines (international, national or regional) }\end{array}$ & 46 & 73 & 83 & 97 \\
\hline Existence of current CKD detection programmes & 6 & 24 & 24 & 32 \\
\hline Availability of dialysis registries & 24 & 48 & 72 & 89 \\
\hline $\begin{array}{l}\text { Availability of academic centres for renal clinical trial } \\
\text { management }\end{array}$ & 12 & 34 & 62 & 63 \\
\hline
\end{tabular}

CKD, chronic kidney disease; eGFR, estimated glomerular filtration rate; ISN, International Society of Nephrology. 
Table 2 Physician awareness of CKD, guideline awareness and adoption across World Bank income groups (adapted from ISN Global Kidney Health Atlas ${ }^{5}$ )

\begin{tabular}{|c|c|c|c|c|c|}
\hline & $\begin{array}{l}\text { World Bank } \\
\text { income group }\end{array}$ & Extremely low (\%) & $\begin{array}{l}\text { Low/below } \\
\text { average (\%) }\end{array}$ & $\begin{array}{l}\text { Moderate/average } \\
(\%)\end{array}$ & $\begin{array}{l}\text { High/above } \\
\text { average (\%) }\end{array}$ \\
\hline \multirow{4}{*}{$\begin{array}{l}\text { Awareness of CKD } \\
\text { by primary care } \\
\text { physicians }\end{array}$} & Low-income & 29 & 35 & 35 & - \\
\hline & Low-middle-income & 13 & 44 & 34 & 9 \\
\hline & $\begin{array}{l}\text { Upper-middle- } \\
\text { income }\end{array}$ & 14 & 55 & 31 & - \\
\hline & High-income & 8 & 58 & 26 & 8 \\
\hline \multirow{4}{*}{$\begin{array}{l}\text { Awareness of CKD } \\
\text { guidelines by non- } \\
\text { nephrologists }\end{array}$} & Low-income & 25 & 63 & - & 13 \\
\hline & Low-middle-income & 17 & 57 & 22 & 4 \\
\hline & $\begin{array}{l}\text { Upper-middle- } \\
\text { income }\end{array}$ & 13 & 42 & 42 & 4 \\
\hline & High-income & - & 46 & 46 & 8 \\
\hline \multirow{4}{*}{$\begin{array}{l}\text { Adoption of CKD } \\
\text { guidelines by non- } \\
\text { nephrologists }\end{array}$} & Low-income & 38 & 50 & - & 13 \\
\hline & Low-middle-income & 36 & 41 & 18 & 5 \\
\hline & $\begin{array}{l}\text { Upper-middle- } \\
\text { income }\end{array}$ & 21 & 46 & 29 & 4 \\
\hline & High-income & 5 & 49 & 38 & 8 \\
\hline
\end{tabular}

CKD, chronic kidney disease; ISN, International Society of Nephrology.

of Action on Nutrition 2016-2025. ${ }^{13}$ Addressing these environmental, behavioural and metabolic risks directly through population strategies is likely to achieve the best outcomes, but will require determined advocacy and sustained political commitment. Interventions must be multifaceted and could include using differential taxation to make healthy food more affordable, with revenue used to support education and health services. Mexico's 'soda tax' introduced in 2014 is one such example. ${ }^{15}$ Therefore we believe the nephrology community has an important role in advocating for policies that have the potential to reduce the burden of preventable kidney disease and associated cardiovascular disease.

The broader global health community now must capitalise on momentum from World Kidney Day and the Global Kidney Health Atlas to ensure CKD is not relegated to a secondary priority within the spectrum of cardiometabolic health. Only then will we be able stem the tide of CKD and achieve high-quality universal healthcare for all who need it.

Twitter Dr Brendon Neuen @brendonIn, Dr Alessandro Demaio @sandrodemaio and Professor Vlado Perkovic @vladoperkovic

Contributors BLN, literature search, interpretation, drafting of manuscript and figures, and coordinating author. SJC, literature search, interpretation, drafting of manuscript. ARD, drafting of manuscript. DWJ, interpretation, drafting of manuscript and figures. VP, interpretation, drafting of manuscript.

Competing interests DWJ is Co-Chair of the International Society of Nephrology Global Kidney Care Atlas. AD is currently a staff member of the World Health Organization. The authors alone are responsible for the views expressed in this publication and they do not necessarily represent the decisions, policy or views of the World Health Organization.

Open Access This is an Open Access article distributed in accordance with the Creative Commons Attribution Non Commercial (CC BY-NC 4.0) license, which permits others to distribute, remix, adapt, build upon this work non-commercially, and license their derivative works on different terms, provided the original work is properly cited and the use is non-commercial. See: http://creativecommons.org/ licenses/by-nc/4.0/

(C) Article author(s) (or their employer(s) unless otherwise stated in the text of the article) 2017. All rights reserved. No commercial use is permitted unless otherwise expressly granted.

\section{REFERENCES}

1. Wang $\mathrm{H}$, Naghavi M, Allen C, et al. GBD 2015 Mortality and Causes of Death Collaborators. Global, regional, and national life expectancy, all-cause mortality, and cause-specific mortality for 249 causes of death, 1980-2015: a systematic analysis for the Global Burden of Disease Study 2015. Lancet 2016;388:1459-544.

2. Tonelli M, Agarwal S, Cass A, et al. How to advocate for the inclusion of chronic kidney disease in a national noncommunicable chronic disease program. Kidney Int 2014;85:1269-74.

3. Anand S, Kondal D, Montez-Rath M, et al. Prevalence of chronic kidney disease and risk factors for its progression: a cross-sectional comparison of Indians living in indian versus U.S. cities. PLoS One 2017;12:e0173554.

4. Liyanage $T$, Ninomiya $T$, Jha V, et al. Worldwide access to treatment for end-stage kidney disease: a systematic review. Lancet 2015;385:1975-82.

5. Bello AK LA, Tonelli M, Okpechi IG, et al. Global Kidney Health Atlas: A report by the International Society of Nephrology on the current state of organization and structures for kidney care across the globe: International Society of Nephrology, Brussels, Belgium. 2017.

6. Thomas B, Matsushita K, Abate KH, et al. Global Cardiovascular and Renal Outcomes of Reduced GFR. J Am Soc Nephrol 2017:ASN.2016050562. [Epub ahead of print].

7. Herrington WG, Smith M, Bankhead C, et al. Body-mass index and risk of advanced chronic kidney disease: prospective analyses from a primary care cohort of 1.4 million adults in England. PLoS One 2017;12:e0173515.

8. Navaneethan SD, Yehnert H, Moustarah F, et al. Weight loss interventions in chronic kidney disease: a systematic review and meta-analysis. Clin J Am Soc Nephrol 2009;4:1565-74.

9. World Health Organization. 2010. Monitoring the Building Blocks of Health Systems: A Handbook of Indicators and Their Measurement Strategies. Geneva: World Health Organization. 
10. Jha V, Garcia-Garcia G, Iseki K, et al. Chronic kidney disease: global dimension and perspectives. The Lancet 2013;382:260-72.

11. Bello AKJD, FeehallyJ, HarrisD, et al. Global Kidney Health Atlas (GKHA): Design and Methods. Kidney International. In Press. 2017.

12. Bello AK, Levin A, Tonelli M, et al. Assessment of Global Kidney Health Care Status. JAMA 2017;317:1864-81.

13. Forouzanfar MH, Alexander L, Anderson HR, et al. Global, regional, and national comparative risk assessment of 79 behavioural, environmental and occupational, and metabolic risks or clusters of risks in 188 countries, 1990-2013: a systematic analysis for the Global Burden of Disease Study 2013. The Lancet 2015;386:2287-323.

14. United Nations Decade of Action on Nutrition.World Health Organization, Geneva, 2016. http://www.who.int/nutrition/GA_ decade_action/en/.

15. Colchero MA, Popkin BM, Rivera JA, et al. Beverage purchases from stores in Mexico under the excise tax on sugar sweetened beverages: observational study. BMJ 2016;352:h6704. 